\title{
HIGH NITROGEN DIETS AND RENAL INJURY
}

\author{
The Dependence of the Injury Upon the Nature of the Nitrog- \\ ENOUS Substance \\ L. H. NEWBURGH AND MARGARET WOODWELL JOHNSTON \\ (From the Department of Internal Medicine, University of Michigan, Ann Arbor)
}

(Received for publication October 27, 1930)

An earlier report from this laboratory dealt with the effect upon the kidneys of the white rat, of diets high in protein from different sources. The first diet contained a mixture of seeds supplemented with casein in order to increase the total protein. A second group of rats received diets in which casein was the only protein. Lean beef muscle was the source of protein for the third diet, whereas beef liver furnished the protein in the fourth diet. Our experience with these diets brought out the significant fact that the extent of the injury was largely determined by the nature of the nitrogenous material employed. Thus we were able to state that "Diets containing 75 per cent of dried liver produce a granular kidney in less than one year, but the same amount of casein fed sixteen months, causes only a moderate tubular injury. The effect of a similar amount of beef muscle is intermediate between these two." Since the casein diets in which all (or almost all) of the nitrogen was present as pure protein, caused only negligible injury; and since the beef muscle and liver diets in which a considerable increment of the nitrogen was present in the form of purines and other nonprotein nitrogenous complexes, worked such marked injury; we were led to suspect that the pure protein in a diet does not harm the kidney, but that the nephropathy has its origin in the nonprotein nitrogenous substances present in animal tissues-such as muscle and liver.

In order to test fhis idea, we fed diets to rats containing 75 per cent of lactalbumin, and wheat and soya bean "gluten" in as large amounts as is consistent with a normal supply of vitamines and salts. These latter two diets contained about 70 per cent of protein. Neither the animal protein (lactalbumin) nor the vegetable proteins, were capable 
of producing demonstrable renal injury. At the end of a year's feeding, the urines as well as the histological sections of the kidneys were normal. A further reason for believing that the pure protein of a diet does not originate renal disease, is to be found in the fact that the excretion of large amounts of urea for a long time does not injure the kidney. We added sufficient urea (1) to an otherwise normal diet to produce a nitrogen metabolism equal to that resulting from a diet containing 40 per cent of protein. Other investigators (2) have had a similar experience.

On the other hand, it is quite clear that the ingestion of animal tissues causes the liberation or formation of something that is highly injurious to the kidneys. As already pointed out, diets high in muscle or liver cause fibrotic renal lesions. However, when equal amounts of liver and beef are fed, it is found that liver is much more injurious than beef. In our earlier paper (1) we pointed out that rats invariably died in less than one year when three fourths of the diet consisted of liver, and the kidneys of such animals were granular due to the large patches of fibrous tissue distributed in the characteristic manner.

More recently diets containing lesser amounts of dried whole beef liver had been fed. The damage caused by 60 per cent of liver seemed to be almost as severe as that found in the earlier series of animals that ate the diet containing 75 per cent of liver.

Diets in which the liver made up 40 per cent of the dry weight were more successfully survived by the rats. They were able to grow at the standard rate and at the end of one year, some of them still looked outwardly well. For example, one such female, ${ }^{1}$ born January tenth, 1929, was placed on the diet on the ninth of February, 1929, when the body weight was 46 grams. Twelve months later the animal weighed 220 grams. The urine at this time contained 1.6 per cent of albumin and 900 casts per cubic centimeter. The kidneys weighed 2.1 grams. The outer surface was finely granular, grayish brown, mottled with pale gray areas.

Microscopically these kidneys showed the same, type of disease as that described for the animals that received the larger amounts of liver (1), but the lesions were, as was to be expected, less extensive.

${ }^{1}$ At autopsy many of our older rats show the chronic purulent pneumonia familiar to other investigators. The lungs of this animal were normal. 
The outstanding features in both cases, were the degeneration of tubular epithelium and the patchy fibrosis.

When the diets contained only 20 per cent of liver, no evidence of renal injury was obtained.

In the search for a more definite cause of this nephropathy, one may think of such a tissue as liver as made up mainly of three types of substances, i.e., (1) the proteins, (2) the large group of nonprotein nitrogenous compounds, and (3) the lipids. Reasons have already been cited for concluding that the renal injury could not be attributed to the proteins. In order to determine which of the other two groups contained the nephrotoxic substances, dried powdered liver was thoroughly extracted with ether and the residue fed. It did not seem necessary to feed the ether soluble fraction since, theoretically, fats are completely oxidized to carbon dioxide and water. Further when such material is incorporated in diets beyond one-third of the dry weight, the rats will not eat enough of it to carry out the experiment.

The ether insoluble residue of liver caused the development of kidney disease in the rats that appeared to be entirely analogus to that produced by whole liver. For example, rat 414 ingested a diet containing 50 per cent of liver residue for twelve months, when it weighed 212 grams and gave the appearance of health. The urine contained 2 per cent of albumin and about 5000 casts per cubic centimeter. At autopsy normal lungs were found. The kidneys weighed 2.1 grams and the outer surface was finely granular and mottled. Histologically these kidneys could not be distinguished from those of the rats that received the whole liver.

Since none of the pure proteins that we fed were capable of causing definite kidney injury, and since the liver from which the lipids had been removed produced severe injury, it seemed highly probable that the nephrotoxic substances were to be found in the nonprotein nitrogenous fraction. It will be recalled that liver is much more damaging to the kidneys than beef muscle in equal amounts; and since liver, like other glandular tissues, is rich in nuclear material, it seemed likely that these nitrogenous substances might be chiefly responsible for the injury.

We accordingly prepared the sodium salt of nucleic acid according to the method of Jones (3) and fed it to rats. The sodium nucleate 
was substituted for the cornstarch in the following basal diet, in such amounts that the nucleate made up 5, 10 or 20 per cent of the diet respectively:

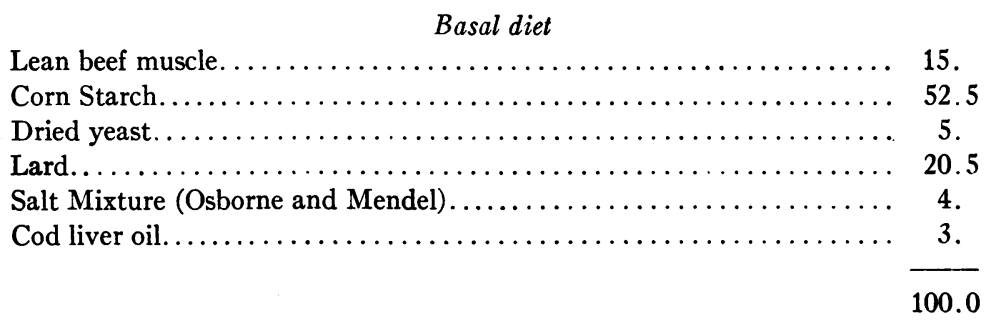

No kidney injury was detectable in the rats that received the diet containing 5 per cent of sodium nucleate.

On the other hand, half of the rats that ate the two higher diets began voiding bloody urine after three to four months, and frequent subsequent inspection of the urines of these animals always revealed gross hematuria. The remaining rats never had macroscopic blood in the urines. Under the microscope the irregular occurrence of red blood cells was recorded. None of the urines contained an abnormally large number of casts. This was the case even when the slightly acid fresh specimens were examined. The absence of casts became the more interesting when it was seen, by means of the microscope, that the nucleic acid was capable of causing extensive renal injury.

A majority of the rats failed to reach the standard adult weight, but the kidney disease can not be attributed to the malnutrition, since the rats that ate the diet containing 5 per cent sodium nucleate had normal kidneys, even though they grew poorly. Furthermore, the animals on the higher diets grew at least as well and showed kidney lesions.

The microscopic study of the kidneys (figs. 1, 2, 3, and 4) showed that the nephropathy produced by nucleic acid is characterized by an extensive formation of fibroblastic tissue and by the hyperplasia of the walls of the arterioles. The amount of new connective tissue was roughly proportional to the concentration of the sodium nucleate in the diet. In the kidneys in which it occurred in the largest amounts, it was distributed in irregular patches and bands throughout the cortex and extended into the medulla. The bands were, however, most fre- 
quent in the outer third of the cortex and, by contraction, caused the granular surface evident to the unaided eye.

The small arteries of the cortex stood out prominently due to the great thickness of the muscular coat. No abnormality of the intima was noted.

Disbursed irregularly through the areas of connective tissue there were numerous small round cells.

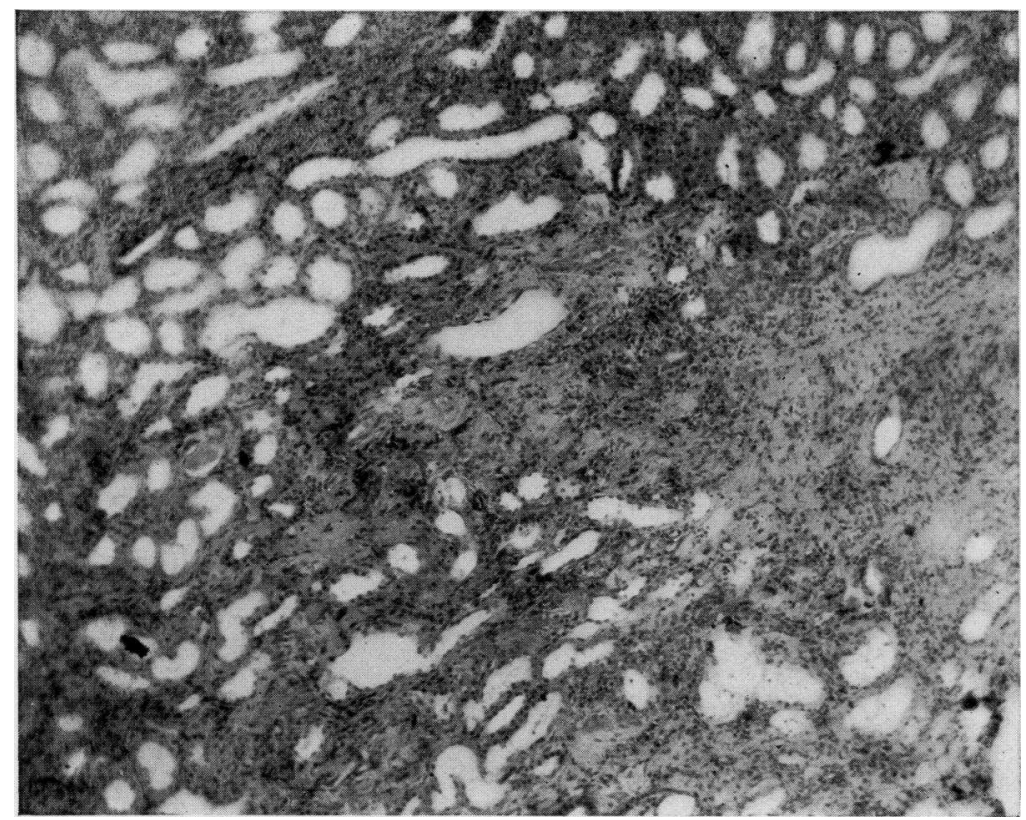

Fig. 1. Part of a Broad Patch of Fibrous Tissue That Extended from the Outer Third of the Cortex Deep into the Medulla

Several of these large fibrous areas were seen in every section of the kidney

No definite disease of the glomeruli themselves could be detected. Some of them imbedded in a patch of fibroblastic tissue were compressed and showed thickening of Bowman's capsule. A few fine adhesions were seen.

The convoluted tubules were frequently dilated. Occasionally the dilatation was great enough to produce a cyst-like cavity. The tubular epithelium showed well marked cloudy swelling. 


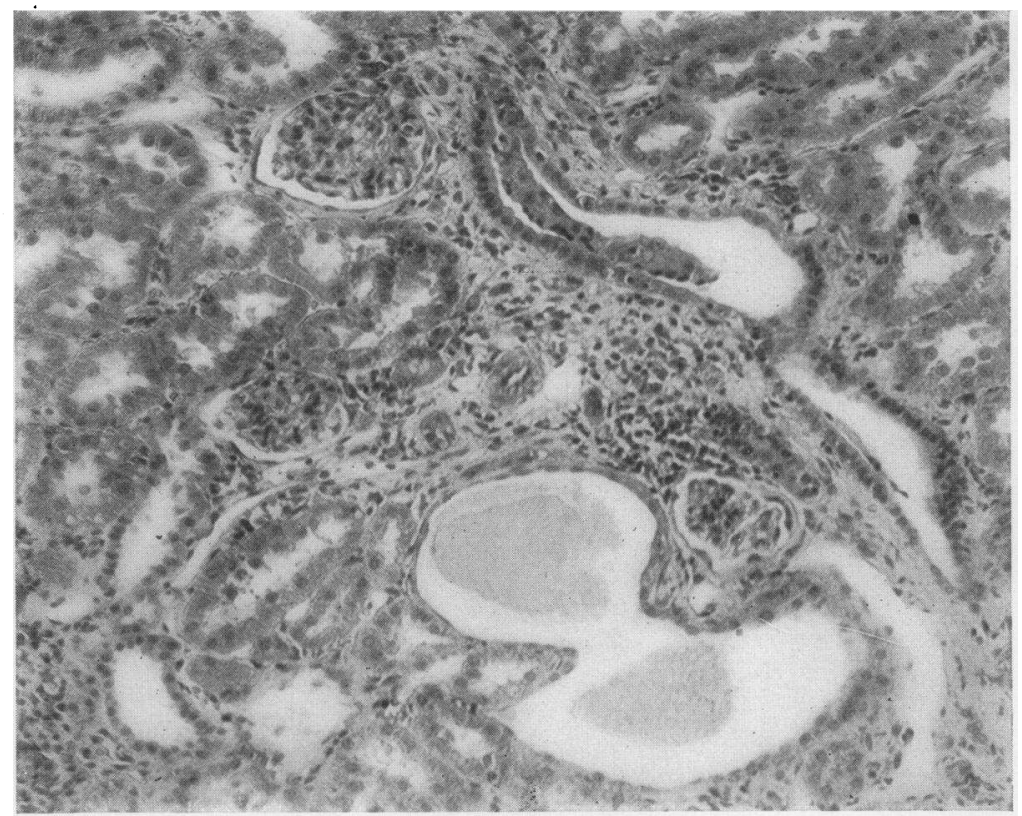

Fig. 2. Smaller Patches of Connective Tissue Were Very Numerous

In the center of the field is a greatly thickened arteriole. The glomeruli appear to be normal.

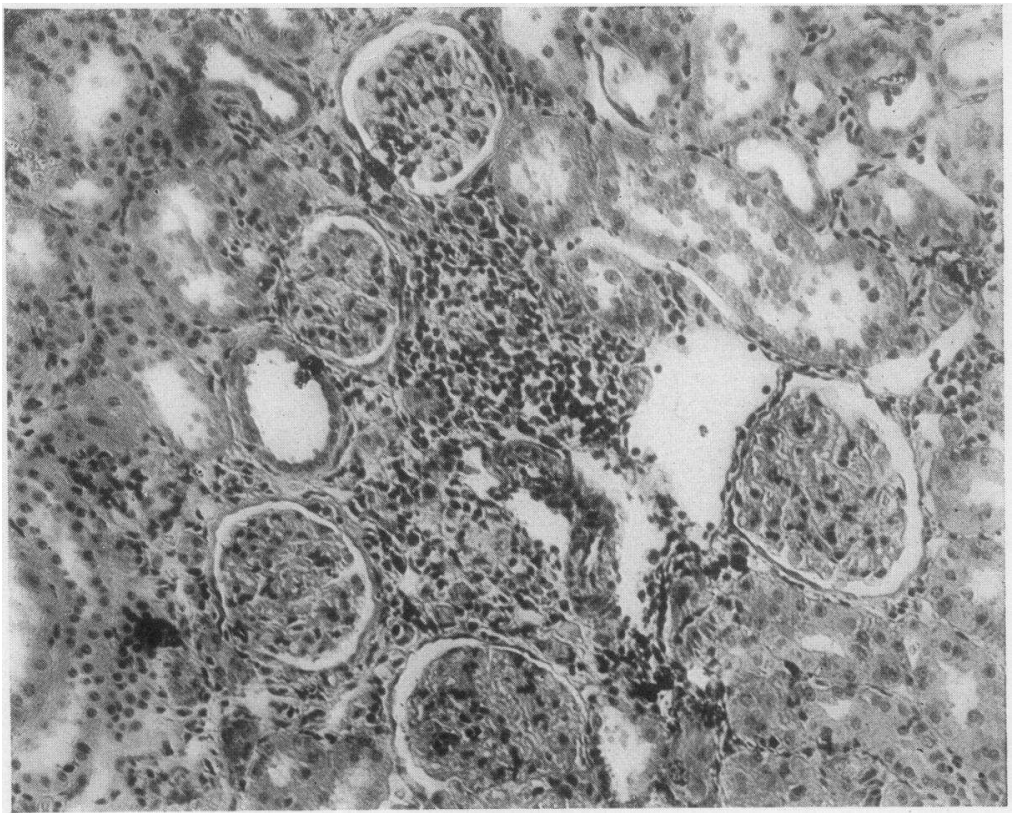

Fig. 3. Scattered through the Cortex Were Areas of This Type, in Which Many Small Round Cells Were Imbedded in the Fibrous Tissue

A thick walled arteriole had been cut longitudinally. Cloudy swelling of the tubular epithelium was marked. 
In the medulla, the tubules contained a considerable amount of calcified coagulum. A few casts were seen.

In the case of the animals that had shown the hematuria, the kidneys, in addition to the above findings, displayed extreme vascular dilatation and very many small and large hemorrhages.

This demonstration that the degradation products of nuclear material are capable of causing kidney disease, brings up the question of the

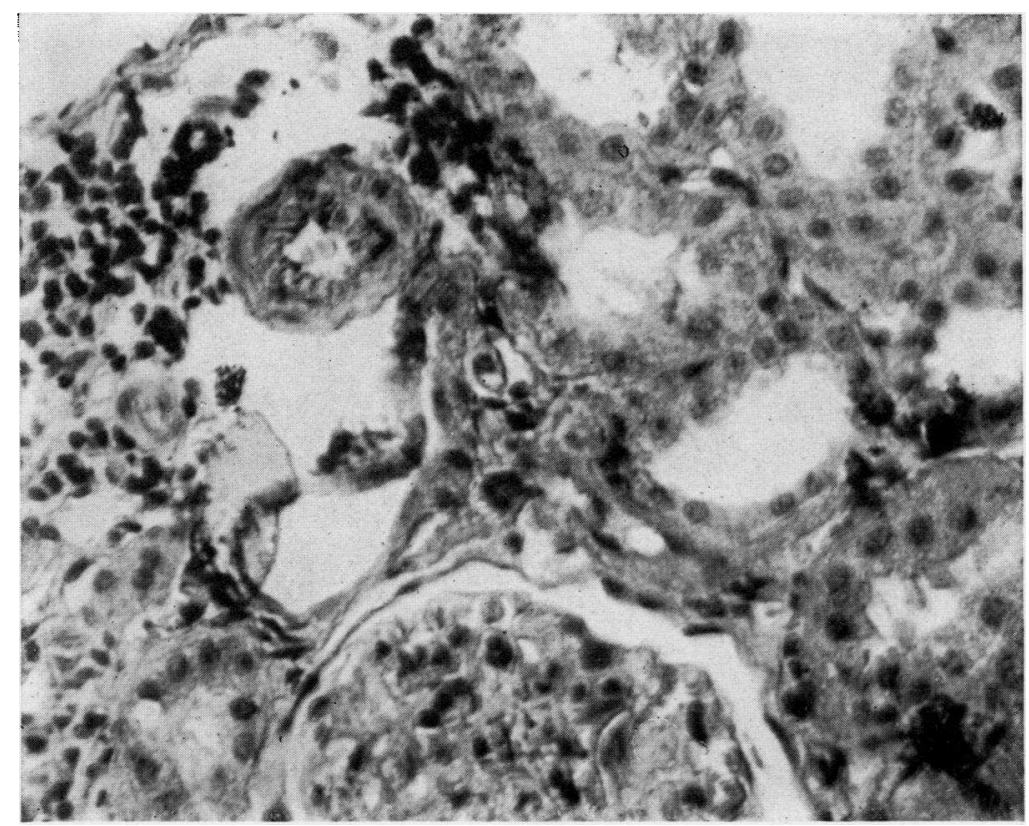

Fig. 4. Higher Magnification of an Arteriole

In the normal rat kidney it is difficult to find arterioles with this magnification because the walls are so thin.

relationship between this fact and the production of nephropathy by animal tissues. The sodium nucleate fed by us contained 13 per cent nitrogen. Theoretically two thirds of it was in the purin form. According to Burian and Schur (4), liver contains 0.12 per cent of purin nitrogen. Dried liver would contain, roughly, three times as much, or 0.4 per cent. A diet made up of 50 per cent of dried liver is definitely nephropathic, and contains only 0.2 per cent purin nitrogen, 
whereas the diet lowest in nucleic acid that injures the kidney contains four times that amount of purin nitrogen. Furthermore, the microscopic appearance of the lesions is different in the two cases. It would, accordingly, appear to be true that liver contains forms of nonprotein nitrogen other than the purins that are nephropathic. Since in the case of muscle the purin nitrogen is only half that of liver, it is even more probable that the purin fraction can only be one of the causes of injury.

\section{CONCLUSIONS}

1. A diet containing as little as $\mathbf{4 0}$ per cent of dried beef liver is nephropathic for the white rat.

2. A diet containing 20 per cent of sodium nucleate produces a granular kidney in eight months or less. Microscopically the disease is characterized by abundance of fibroblastic tissue and by thickening of the media of the arterial wall.

3. A diet containing 10 per cent of sodium nucleate produces similar lesions of lesser degree.

\section{BIBLIOGRAPHY}

1. Newburgh, L. H., and Curtis, A. C., Arch. Int. Med., 1928, xlii, 801. Production of Renal Injury in the White Rat by the Protein of the Diet.

2. Osborne, T. B., Mendel, L. B., Park, E. A., and Winternitz, M. C., J. Biol. Chem., 1927, lxxi, 317. Physiological Effects of Diets Unusually Kich in Protein or Inorganic Salts.

Hinman, F., J. Urol., 1923, ix, 289. Renal Counterbalance.

Addis, T., MacKay, E. M., and MacKay, L. L., J. Biol. Chem., 1926, lxxi, 139. The Effect on the Kidney of Long Continued Administration of Diets Containing an Excess of Certain Food Elements.

3. Jones, Walter, Nucleic Acids. London, Longmans, Green and Co., 2nd Ed., 1920.

4. Burian, R., and Schur, H., Arch. f. d. ges. Physiol., 1900, lxxx, 308 . Ueber die Stellung der Purinkörper im menschlichen Stoffwechsel. 